\title{
PERAN MEMBACA AWAL TERHADAP PEMAHAMAN BACAAN PADA SISWA KELAS IV SEKOLAH DASAR
}

\author{
Amalia Novita Retaminingrum ${ }^{1}$, Sri Tiatri ${ }^{2}$ \& Soemiarti Patmonodewo ${ }^{3}$ \\ ${ }^{l}$ Program Studi Psikologi Jenjang Magister, Universitas Tarumanagara, Jakarta \\ Email : amalia.novita@highscope.or.id \\ ${ }^{2,3}$ Fakultas Psikologi, Universitas Tarumanagara, Jakarta \\ Email : sri.tiatri@untar.ac.id
}

\begin{abstract}
ABSTRAK
Tujuan dari penelitian ini adalah untuk menguji peran kelancaran membaca awal terhadap pemahaman bacaan. Partisipan adalah 150 siswa kelas empat. Partisipan diberi satu set asesmen yang mencakup beberapa komponen kelancaran membaca awal dan pengukuran atas pemahaman bacaan fiksi dan non fiksi. Kelancaran membaca awal diukur dengan Early Grade Reading Assessment yang mengukur letter name identification, segmentation (phoneme or syllables), non word reading, oral reading fluency, reading comprehension, listening comprehension, vocabulary, dan dictation. Pemahaman bacaan fiksi dan non fiksi diukur melalui tes yang dikembangkan berdasarkan Curriculum Based Assessment dari Kurikulum 2013 Indonesia. Analisis regresi dilakukan pada penelitian ini, dan hasil penelitian menunjukkan bahwa ada dua komponen kelancaran membaca awal yang berhubungan dengan pemahaman bacaan.

Kata kunci: kelancaran membaca awal, pemahaman bacaan, egra, early grade reading assessment.
\end{abstract}

ABSTRACT

The goal of this study was to examine the role of early reading fluency in reading comprehension. Participants were 150 fourth-grade children. They were given an assessment that included multiple components of early reading fluency, and a fiction and non fiction text to measure their reading comprehension. For early reading fluency, this study used Early Grade Reading Assessment which measures of letter name identification, segmentation (phoneme or syllables), non word reading, oral reading fluency, reading comprehension, listening comprehension, vocabulary, and dictation. For fiction and non-fiction reading comprehension, this study use Curriculum Based Assessment from 2013 Indonesian Curriculum. Regression analyses were undertaken, the results showed that there are two component of early reading fluency which related to reading comprehension.

Keywords: Early Reading Fluency, Reading Comprehension, EGRA, Early Grade Reading Assessment,

\section{PENDAHULUAN}

\section{Latar Belakang}

Membaca merupakan salah satu kemampuan dasar yang wajib dimiliki oleh individu di abad sekarang dan yang akan datang. Kemampuan membaca menjadi hal yang penting dalam suatu masyarakat sebab melalui membaca dapat diserap berbagai informasi dan wawasan pengetahuan untuk mengembangkan peradaban masyarakat tersebut (Krismanto, Khalik \& Sayidiman, 2015). Esensi dari membaca adalah pemahaman tentang apa yang dibaca (Burns, Roe, \& Ross,1996). Pemahaman bacaan didefinisikan sebagai proses strategis dimana pembaca membangun atau menetapkan makna bacaan dengan menggunakan petunjuk dalam teks dan pengetahuan mereka sendiri (Speece \& Cooper, 2002). Memahami bacaan adalah proses memaknai sesuatu sebuah tulisan. Pemahaman bacaan melibatkan pemahaman mengenai kosa kata dan melihat hubungan di antara kata-kata, konsep, dan tujuan penulis (Sinambela, Manik, \& Pangaribuan, 2015).

Language and Reading Research Consortium dan Logan (2917) menyebutkan beberapa tititk tekanan dalam pemahaman membaca, salah satunya adalah terdapat peranan membaca awal terhadap pemahaman membaca. Faktor-faktor dalam proses pemahaman tersebut menyebabkan kegiatan membaca sebagai kegiatan yang rumit (NICHD, 2000). Guna memahami sebuah kalimat, seseorang harus mampu mengidentifikasi representasi fonologis, ortografi, dan semantik dari informasi yang ada untuk membentuk pemahaman dari makna informasi tersebut (Kendeou, Smith, \& O'Brien, 2013). Logan (1997) yang mengungkapkan bahwa sebagian besar anak-anak 
yang kesulitan membaca di sekolah dasar mengalami kesulitan dalam pemahaman bacaan yang diperlukan untuk memecahkan kode dan memahami kata-kata di cetak secara akurat. Schwanenflugel dan Knapp (2016) mengungkapkan bahwa membaca awal merupakan tahapan proses belajar membaca bagi siswa sekolah dasar kelas awal. Siswa belajar untuk memperoleh kemampuan dan menguasai teknik-teknik membaca dan menangkap isi bacaan dengan baik. Banyak penelitian telah menemukan korelasi antara kemampuan membaca awal anak-anak dan pengukuran pemahaman membaca (Fuchs, Fuchs, Hosp \& Jenkins, 2001). Hasil penelitian dari USAID dengan alat ukur EGRA atau Early Grade Reading Assessment juga mengungkapkan komponen-komponen dalam membaca awal, yaitu: a) pengenalan huruf, b) membedakan bunyi awal, c) membaca kelompok huruf yang tidak bermakna, d) membaca nyaring, e) pemahaman bacaan, f) pemahaman dengaran, g) kosakata bahasa Indonesia, dan h) dikte (Dubeck \& Gove, 2105).

Temuan di lapangan berdasarkan observasi dan wawancara yang dilakukan peneliti pada tanggal 15 September 2018 di SD X di kota Bogor mengindikasikan temuan yang serupa dengan penelitian-penelitian sebelumnya di atas. Nilai mata pelajaran Bahasa Indonesia kelas IV di SD $\mathrm{X}$ di kota Bogor pada materi tentang pemahaman bacaan menunjukkan hanya 53\% siswa yang mencapai kemampuan di atas KKM berdasarkan kurikulum 2013 yakni 70. Hasil wawancara menambahkan temuan peneliti bahwa masalah-masalah pada pemahaman bacaan anak yang rendah juga disebabkan oleh belum lancarnya beberapa anak dalam membaca. Observasi dan wawancara ditujukan pad akelas IV Sekolah Dasar ini dilakukan karena pemahaman bacaan menjadi indikator kesukseksan membaca sesuai dengan kompetensi dasar dan inti kurikulum 2013.

Permasalahan mengenai rendahnya kemampuan membaca siswa di kelas IV Sekolah Dasar perlu segera ditindaklanjuti. Salah satu upaya yang dapat dilakukan untuk menindaklanjuti hal tersebut adalah melalui pengujian kemampuan dasar membaca anak dengan alat ukur yang sudah memiliki standar. Alat ukur yang dapat digunakan untuk melihat kemampuan membaca awal anak adalah EGRA atau Early Grade Reading Assessment. Alat ukur ini memiliki delapan subtask yang mewakili komponen membaca awal. Alat tes EGRA telah digunakan lebih dari 65 negara yang berguna untuk memahami keterampilan membaca saat ini atau melacak pertumbuhan longitudinal (Jimenez, Gove, Crouch \& Rodriguez, 2014). Penelitian sebelumnya dengan menggunakan alat tes EGRA di Indonesia, dilakukan oleh USAID pada tahun 2014 untuk melihat gambaran keseluruhan kemampuan membaca awal di setiap wilayah di Indonesia. Hasil dari penelitian tersebut mengemukakan bahwa belum meratanya kemampuan membaca awal anak di Indonesia (Jimenez, Gove, Crouch \& Rodriguez, 2014). Penelitian mengenai peranan membaca awal dengan pemahaman bacaan ini belum pernah dilakukan di Indonesia. Seperti yang telah dijabarkan di atas bahwa membawa awal merupakan faktor yang melatarbelakangi kemampuan pemahaman bacaan anak, maka peneliti tertarik untuk melakukan penelitian mengenai peran kemampuan membaca awal terhadap pemahaman bacaan siswa kelas IV sekolah dasar.

\section{Rumusan Masalah}

Apakah terdapat peranan dari komponen membaca awal terhadap pemahaman bacaan siswa kelas IV Sekolah Dasar?

\section{METODE PENELITIAN}

Peneliti menggunakan metode penelitian non-eksperimental yang memiliki variabel-variabel tertentu yang akan diteliti sudah ada di dalam partisipan penelitian dan bersifat alamiah sehingga peneliti tidak perlu melakukan manipulasi pada variabel-variabel tertentu. Metode penelitian ini mengacu pada pembahasan metode oleh Kerlinger (1992). Penelitian ini bertujuan untuk melihat 
peran membaca awal terhadap pemahaman bacaan sebagai dasar strategi pengajaran di kelas. Variabel dependent dalam penelitian ini adalah Pemahaman Bacaan atau Reading Comprehension. Variabel independent dalam penelitian ini adalah komponen-komponen dalam kemampuan membaca awal. Data-data tambahan yang digunakan dalam penelitian ini diperoleh melalui observasi dan wawancara.

\section{Partisipan Penelitian}

Penelitian ini dilakukan kepada 150 partisipan di Sekolah Dasar X dengan karakteristik: (a) partisipan adalah murid-murid kelas 4 sekolah dasar, (b) usia partisipan antara 9 - 10 tahun, (c) partisipan adalah murid di Sekolah X sejak kelas 1 SD. Pengkategorian partisipan dilakukan agar penelitian dapat menjadi lebih teliti dan lebih terfokus pada partisipan penelitian.

\section{Instrumen Penelitian}

Penelitian ini merupakan penelitian kuanitatif yang menggunakan teknik penyebaran survey dan kuesioner kemudian dilanjutkan dengan wawancara mendalam. Instrumen yang digunakan dalam penelitian ni adalah alat perekam, alat tulis, buku catatan, dan pedoman wawancara yang berisi daftar pertanyaan yang telah disusun sebelumnya oleh peneliti.

\section{Prosedur Penelitian}

Penelitian ini diawali dengan meminta ijin kepada pihak yayasan sekolah dengan mengajukan proposal penelitian. Proposal tersebut berisikan mengenai latar belakang masalah umum, tujuan penelitian, dan proses pengambilan data. Peneliti melakukan presentasi mengenai proposal tersebut pada tanggal 14 September 2018. Setelah proses dilakukan, maka peneliti mendapatkan persetujuan dari pihak sekolah.

Penelitian dimulai pada tanggal 22 September 2018 hingga 28 September 2018. Pengambilan data dilakukan oleh peneliti dan 2 assessor tambahan. Dua assessor tambahan tersebut memiliki latar belakang S1 Psikologi dan telah dilatih untuk melakukan pengambilan data. Di awal kegiatan pengambilan data, peneliti terlebih dahulu memperkenalkan diri dan tim. Peneliti menjelaskan maksud dan tujuan datang ke sekolah tersebut kemudian mendata murid-murid yang berada di kelas 4 SD. Peneliti kemudian membagi murid-murid ke dalam tiga kelompok, dan memanggil murid satu persatu untuk ukur kemampuannya dalam kemampuan membaca dan pemahaman. Setiap subyek membutuhkan waktu selama 20 menit untuk dapat menyelesaikan dua rangkaian tes.

Data penelitian selanjutnya dimasukkan ke dalam program SPSS, diolah dan dianalisis untuk mengetahui peran dari masing-masing komponen dalam kemampuan membaca awal. Hasil analisis dibahas dalam uraian berikut ini.

\section{HASIL DAN PEMBAHASAN}

Berdasarkan data yang diperoleh, dilakukan uji pengaruh variabel independen. Dari analisa data menggunakan regresi linear (data residu normal) diperoleh hasil dari perhitungan nilai regresi diperoleh juga nilai $\mathrm{R}=0.329$, koefisien determinasi $\mathrm{R}^{2}=0.108$, nilai ini diperoleh dari pengkuadratan dari koefisien korelasi (0.329 x 0.329). Hal ini juga menunjukkan bahwa $10.8 \%$ sumbangan Komponen Membaca Awal terhadap Pemahaman bacaan Non Fiksi sedangkan sisanya dipengaruhi faktor lain $(100 \%-10.8=89.2 \%)$. Dengan demikian terdapat peran Komponen Membaca Awal terhadap Pemahaman bacaan Non Fiksi.

Berdasarkan analisis regresi juga dapat diamati bahwa nilai $\mathrm{F}=2.141$ dan $\mathrm{p}=0.036<0.05$ artinya terdapat pengaruh variabel Komponen Membaca Awal terhadap Pemahaman bacaan Non 
Fiksi secara simultan (bersama-sama). Analisis regresi lebih lanjut juga menunjukkan komponen yang paling memengaruhi Pemahaman bacaan Non-Fiksi. Hal tersebut dapat dilihat dari nilai t, dari hasil pengolahan data diperoleh nilai yang paling berperan adalah Kosa Kata Bahasa Indonesia terhadap Pemahaman bacaan Non-Fiksi dengan nilai $t=2.473$ dan $p=0.015<0.05$. Artinya, terdapat peran yang positif dan signifikan dari Kosa Kata Bahasa Indonesia terhadap Pemahaman bacaan Non-Fiksi. Selain itu, juga diperoleh data nilai t untuk komponen yang lain, namun komponen lain tersebut tidak menunjukkan peran yang signifikan. Hasil selengkapnya dapat dilihat pada tabel 1.

Tabel 1

Hasil Uji t Komponen Membaca Awal terhadap Pemahaman Bacaan Non Fiksi

\begin{tabular}{|c|c|c|c|}
\hline Variabel Independen & $\mathbf{T}$ & $\mathbf{p}$ & Keterangan \\
\hline Pengenalan Huruf & -0.907 & 0.366 & Tidak signifikan \\
\hline Bunyi Awal & -0.416 & 0.678 & Tidak signifikan \\
\hline $\begin{array}{l}\text { Kelompok Huruf } \\
\text { tak Bermakna }\end{array}$ & 1.122 & 0.264 & Tidak signifikan \\
\hline Membaca Nyaring & 1.228 & 0.221 & Tidak signifikan \\
\hline Pemahaman bacaan & 0.423 & 0.673 & Tidak signifikan \\
\hline $\begin{array}{l}\text { Pemahaman } \\
\text { Dengaran }\end{array}$ & -0.968 & 0.335 & Tidak signifikan \\
\hline $\begin{array}{l}\text { Kosakata Bahasa } \\
\text { Indonesia }\end{array}$ & 2.473 & 0.015 & Signifikan \\
\hline Dikte & 1.743 & 0.084 & Tidak signifikan \\
\hline
\end{tabular}

Dependent Variable: Pemahaman bacaan Non-Fiksi

Uraian di atas adalah mengenai pengolahan data Pemahaman Bacaan Non-Fiksi. Selanjutnya mengenai Pemahaman Bacaan Fiksi. Pengolahan data menggunakan regresi linear (data residu normal) kedua diperoleh hasil dari perhitungan nilai regresi diperoleh juga nilai $\mathrm{R}=0.449$, koefisien determinasi $\mathrm{R}^{2}=0.202$, nilai ini diperoleh dari pengkuadratan dari koefisien korelasi (0.449 x 0.449). Hal ini juga menunjukkan bahwa $20.2 \%$ sumbangan Komponen Membaca Awal terhadap Pemahaman bacaan Fiksi sedangkan sisanya dipengaruhi faktor lain (100\% - 20.2 $=79.8 \%$ ). Dengan demikian terdapat peran Komponen Membaca Awal terhadap Pemahaman Bacaan Fiksi.

Berdasarkan analisis regresi juga dapat diamati bahwa nilai $\mathrm{F}=4.454$ dan $\mathrm{p}=0.000<0.05$ artinya terdapat pengaruh variabel Komponen Membaca Awal terhadap Pemahaman bacaan Fiksi secara simultan (bersama-sama). Berdasarkan analisis regresi juga dapat dilihat komponen yang paling memengaruhi Pemahaman Bacaan Fiksi. Berdasarkan hasil pengolahan data diperoleh nilai yang paling berperan adalah Kelompok Huruf yang Tidak Bermakna terhadap Pemahaman bacaan Non-Fiksi dengan nilai $\mathrm{t}=3.296$ dan $\mathrm{p}=0.001<0.05$ artinya $\mathrm{H}_{0}$ tidak dapat diterima dan $\mathrm{H}_{1}$ diterima.

Jadi terdapat peran yang positif dan signifikan dari Huruf yang tak Bermakna terhadap Pemahaman bacaan Non-Fiksi. Untuk peran signifikan yang kedua ditemukan pada Kosa Kata Bahasa Indonesia terhadap Pemahaman bacaan Non-Fiksi dengan nilai $t=3.239$ dan $p=0.001$ $<0.05$. Jadi terdapat peran yang positif dan signifikan dari Kosa Kata Bahasa Indonesia terhadap 
Pemahaman bacaan Non-Fiksi. Selanjutnya juga diperoleh data nilai t untuk variabel yang lain tidak menunjukkan pengaruh yang signifikan. Hasil selengkapnya dapat dilihat pada tabel 2.

Tabel 2

Hasil Uji t Komponen Membaca Awal terhadap Pemahaman Bacaan Fiksi

\begin{tabular}{|c|c|c|c|}
\hline Variabel Independen & $\mathbf{T}$ & $\mathbf{P}$ & Keterangan \\
\hline Pengenalan Huruf & -0.468 & 0.641 & Tidak signifikan \\
\hline Bunyi Awal & 0.362 & 0.718 & Tidak signifikan \\
\hline $\begin{array}{l}\text { Kelompok Huruf tak } \\
\text { Bermakna }\end{array}$ & 3.296 & 0.001 & Signifikan \\
\hline Membaca Nyaring & 0.249 & 0.804 & Tidak signifikan \\
\hline Pemahaman bacaan & 0.552 & 0.582 & Tidak signifikan \\
\hline $\begin{array}{l}\text { Pemahaman } \\
\text { Dengaran }\end{array}$ & -0.155 & 0.877 & Tidak signifikan \\
\hline $\begin{array}{l}\text { Kosakata Bahasa } \\
\text { Indonesia }\end{array}$ & 3.239 & 0.001 & Signifikan \\
\hline Dikte & -0.453 & 0.651 & Tidak signifikan \\
\hline
\end{tabular}

Dependent Variable: Pemahaman Bacaan Fiksi

\section{KESIMPULAN DAN SARAN}

Berdasarkan hasil penelitian mengenai peran membaca awal terhadap pemahaman bacaan siswa kelas IV Sekolah Dasar, ditemukan dua komponen yang berperan pada pemahaman bacaan fiksi dan non-fiksi. Pada Pemahaman Bacaan Fiksi, komponen membaca awal yang memiliki peranan signifikan adalah membaca Kelompok Huruf Tak Bermakna dan Kosakata Bahasa Indonesia. Sedangkan pada Pemahaman bacaan Non-Fiksi, peranan signifikan ditemukan pada Kosakata Bahasa Indonesia.

Saran pada peneliti lain agar melakukan penelitian lebih mendalam dengan menggunakan variabel tambahan untuk melihat peranan pemahaman bacaan. Terdapat faktor-faktor penentu keberhasilan pemahaman bacaan yang belum diteliti. Dengan ditelitinya faktor-faktor tersebut maka hasil yang didapat akan lebih kaya dan beragam. Guna mendapatkan hasil yang lebih menyeluruh, disarankan agar dapat dibuat juga penelitian yang menyeluruh mengenai kemampuan membaca awal pada anak sekolah dasar, mulai dari tingkatan kelas 1 hingga kelas 6 SD. Data tersebut nantinya dapatnya dikelompokkan berdasarkan kemampuan anak sehingga intervensi selanjutnya dapat lebih tepat sasaran.

\section{Ucapan Terima Kasih (Acknowledgement)}

Penulis mengucapkan terima kasih sebesar-besarnya kepada para pemimpin, guru dan siswa sekolah HS Indonesia, atas kesempatannya untuk dapat melaksanakan pengambilan data, melakukan wawancara dan observasi terkait dengan penelitian ini. 


\section{REFERENSI}

Krismanto, W., Khalik, A., \& Sayidiman. (2015). Meningkatkan kemampuan membaca pemahaman melalui metode survey, question, read, recite, review (SQ3R) pada siswa kelas IV SD Negeri 46 Parepare. Jurnal Publikasi Pendidikan, 2088-2092.

Burns, P.C., Roe, B.D., \& Ross, E.P. (1996). Teaching Reading in Today's elementary School (Third Edition). Boston: Houghton Mifflin Company.

Cain, K., \& Oakhill, J. (2006). Profiles of children with specific reading comprehension difficulties. British Journal of Educational Psychology, 76, 683-696. DOI : 10.1348/000709905X67610

Dubeck, M.M., \& Gove, A. (2015). The Early Grade Reading Assessment (EGRA) : Its theoretical foundation, purpose, and limitations. International Journal of Educational Development. RTI International : United States.

Fuchs, L., Fuchs, D., Hosp, M., \& Jenkins, J. (2001). Oral reading fluency as an indicator of reading competence: A theoretical, empirical, and historical analysis. Scientific Studies of Reading, 5, 239-256.

Kendeou, P., Smith, E. R., \& O’Brien, E. J. (2013). Updating during read- ing comprehension: Why causality matters. Journal of Experimental Psychology: Learning, Memory, and Cognition, 39(3), 854-865.

Language and Reading Research Consortium \& Logan, J. (2017). Pressure Points in Reading Comprehension : A Quantile Multiple Regression Analysis. Journal of Educational Psychology, Vol. 109, No. 4, 451 - 462. DOI : 10.1037/edu0000150.

Sinambela, E, Manik, S, \& Pangaribuan, R. E (2015). Improving Students' Reading Comprehension Achievement by Using K-W-L Strategy. English Linguistics Research

Logan, G. D. (1997). Automaticity and reading: Perspectives: from the instance theory of automatization. Reading and Writing Quarterly, 13, 123-146.

Schwanenflugel, P. J., \& Knapp, N. F. (2016). The psychology of reading: Theory and applications. New York, NY: Guilford Press.

Jimenez, J.E., Gove, A., Crouch, L., \& Rodriguez, C. (2014). Internal structure and standardized scores of the Spanish adaptation of the EGRA (Early Grade Reading Assessment) for early reading assessment. Psicothema, 26(4), 531-537. doi: 10.7334/psicothema2014.93.

Olson, R. K., Datta, H., Gayan, J., \& DeFries, J. C. (1999). A behavioral-genetic analysis of reading disabilities and component processes. In R. M. Klein \& P. A. McMullen (Eds.), Converging methods for understanding reading and dyslexia (pp. 133-153). Cambridge, MA: MIT Press.

Perfetti, C. A. (1985). Reading Ability. New York, NY: Oxford University Press. 